\title{
Abreviação em Relações de Bebês com seus Pares de Idade ${ }^{1}$
}

\author{
Carolina Alexandre Costa \\ Katia Souza Amorim ${ }^{2}$ \\ Universidade de São Paulo
}

\begin{abstract}
RESUMO - Considerando relações no primeiro ano de vida, a abreviação da comunicação é entendida como processo em que elementos negociados aparecem, gradativamente, de forma abreviada nas interações. Esse processo tem sido estudado, fundamentalmente, em relações mãe-bebê. Objetivou-se, assim, verificar abreviação em relações de bebês com pares de idade. Baseou-se em videogravações de bebês em creche. Os sujeitos são um casal de gêmeos (11m) e seus parceiros preferenciais (9-14m). Episódios interativos foram transcritos e analisados microgeneticamente. A abreviação foi identificada nos comportamentos dos bebês, sendo diferenciada nas várias díades. Dependeu do parceiro e das formas de coconstrução das relações e dos recursos de negociações (choro, olhar, balbucios) utilizados entre eles, ao longo do tempo e situações. Implicações teóricas e práticas são apontadas.
\end{abstract}

Palavras-chave: abreviação, interação entre bebês, microgenética, creche

\section{Abbreviation within Peer Infant's Relations}

\begin{abstract}
In the context of relationships of infants in their first year of life, abbreviation of communication can be understood as a process in which elements that were extensively negotiated, gradually appear in an abbreviated way during interactions. This process has been mainly studied in mother-infant relationships. Thus, the purpose of this study was to verify if abbreviation could also be observed in infants' relationships with peers. Data were composed by video recordings regarding infants' attendance at a daycare center. Subjects were a pair of twins (11 months) and two of their favorite playmates (9-14 months). Interactive episodes were microgenetically transcribed and analyzed. Abbreviation was identified in babies' communication, presenting differently within each dyad. Its characteristics mostly depended on the partner, established relationships, and negotiations means used (crying, looking, babbling) between them, through time and situations. Theoretical and practical implications are highlighted.
\end{abstract}

Keywords: Abbreviation, interaction among babies, microgenetic, daycare centre

Na Psicologia do Desenvolvimento, diversas são as perspectivas para a compreensão e o estudo do bebê. Algumas delas atribuem lugar de destaque ao papel do outro social neste processo (Wallon, 1979; Vygotsky, 1991; Fogel, 1992; Seidl Moura \& Ribas, 2000; Rossetti-Ferreira, Amorim \& Silva, 2004; Sinha \& Rodriguez, 2008; Amorim, 2010). As interações bebê-outro são vistas assim como responsáveis não só pela sobrevida do bebê, como pela mediação bebêmundo. Os comportamentos da criança e sua inserção no meio seriam, então, recortados e interpretados pelos outros segundo as concepções construídas naquela cultura (Bruner, 1997; Rossetti-Ferreira, Amorim \& Silva, 2004).

No processo, em suas várias relações, o bebê passa a fazer uso de recursos comunicativos e significados apreendidos no ambiente cultural (Amorim \& Rossetti-Ferreira, 2008). O bebê é visto, portanto, como se encontrando mergulhado na linguagem e como parte do processo de construção de significados (Correia, 2009). Tal construção se daria através do gesto e de toda a sua corporeidade (Amorim \& RossettiFerreira, 2008), como discute também Vallotton (2011), servindo tanto como a fundação para o aprendizado da

1 Projeto desenvolvido com financiamento PIBIC/CNPq e FAPESP

2 Endereço para correspondência: Faculdade de Filosofia, Ciências e Letras de Ribeirão Preto, Av. Monte Alegre, 3.900, Campus da Universidade de São Paulo, Ribeirão Preto, São Paulo, Brasil. CEP: 14.040-901.E-mail: katiamorim@ffclrp.usp.br linguagem, como assentando a base para a criação da própria linguagem Goldin-Meadow (2007).

Ao discutir a interação do bebê com o adulto, Gerbelli (2006) destaca a importância do olhar, em que seu direcionamento representa forma de transmitir sinais socialmente relevantes. O olhar não é considerado simplesmente visão, mas interação social em potencial, mostrando-se como importante elemento comunicativo (Belini \& Fernandes, 2007; Guimarães, 2008; Êlmor, 2009; Amorim, Anjos e Rossetti-Ferreira, 2012).

Mais ainda, destaca-se a ocorrência do estabelecimento da atenção conjunta. Segundo Tomasello (2003), aquela se estabeleceria em torno do nono mês de vida, em que os bebês começam a olhar, de modo flexível e confiável, para onde os adultos estão olhando. A atenção conjunta seria, então, a capacidade do bebê de coordenação da atenção entre o parceiro e o objeto que interessa a ambos. Segundo o autor, esse compartilhamento da atenção revela um marco no desenvolvimento, já que o bebê passa a ser capaz de monitorar, pelas pistas interativas, a atenção, o comportamento e a ação do adulto.

Nessa perspectiva, o bebê é entendido como agente ativo, relacionando-se com diferentes parceiros sociais e sendo capaz não só de (re)agir a eles, como também de mobilizá-los através de seu equipamento sensorial e expressivo (Wallon, 1979; Fogel, 1992; Carvalho, 1998; Ribeiro \& Bussab, 1998). Como referem Carvalho, Müller e Sampaio (2009), tem 
se fortalecido a visão do bebê como organismo finamente ajustado, para obter do mundo aquilo que é essencial a sua sobrevivência: contato e interação com o outro. Tais competências viabilizariam a comunicação e a constituição de sua subjetividade com e através do outro.

A interação é, em algumas dessas abordagens, considerada para além dos momentos em que as pessoas agem conjuntamente, contemplando também a regulação recíproca, implícita e não necessariamente intencional entre os parceiros. O comportamento pode, dessa maneira, ser regulado mesmo à distância; e, mesmo que os parceiros não saibam que regulam o comportamento do outro (Carvalho; Império-Hamburger; \& Pedrosa, 1996).

Carvalho e colaboradores indicam que, no campo interativo, entre os parceiros sociais, há interesse pelo outro, orientação de comportamentos dirigidos ao e derivados pelo outro. O campo interativo apresenta, portanto, características dialógicas, sendo definido pelos componentes em interação, ao mesmo tempo em que os constitui, dando-se a construção e persistência de significados. As autoras afirmam ainda que o processo no qual uma informação adquire um significado ocorre quando um movimento é selecionado do campo interacional. E a este movimento é atribuído um significado próprio, determinado pelas interações da díade, de forma que as ações dos integrantes passam a ser ajustadas. Cria-se, assim, a possibilidade de comunicar ao(s) outro(s) esse(s) significado(s) e de regular a própria ação e a daquele(s) outro(s). Um novo código passa a vigorar com significados particulares construídos no processo interativo (Carvalho et al., 1996 ).

Lyra (2000) e Lyra e Rossetti-Ferreira (1995), ao tratarem das interações de bebês com adulto nos primeiros meses, discutem a abreviação dos padrões de organização do sistema de comunicação. Nessa perspectiva, desenvolveram o modelo Estabelecimento, Extensão e Abreviação (EEA), que contribui à análise dos períodos de quase estabilidade no sistema de comunicação mãe-bebê. Os padrões do EEA definem, respectivamente: 1) a partilha de elemento pela díade; 2) o elemento anteriormente partilhado passa a ser fundo e novos elementos são estabelecidos como figuras; e, 3) as trocas passam a se dar por ajustamento mútuo, rápido e fácil.

Lyra (2007) propõe que o processo da comunicação mãebebê obedeça a essa sequência de padrões organizacionais, que se distinguem pelas diferentes características das trocas mãe-bebê. Esses seriam caracterizados por uma dinâmica, que exerce atividade de recorte, destaque ou diferenciação.

Tais processos, como outros mencionados acima, vêm sendo estudados centralmente na relação mãe-bebê. No entanto, no que se refere à abreviação dos padrões de organização do sistema de comunicação, o trabalho de Amorim, Anjos e Rossetti-Ferreira (2012), a partir de processos interativos de bebês em creche, apresentou indícios de que abreviação foi observada nas interações bebê-bebê (particularmente, na relação de um casal de irmãos gêmeos). Interrogou-se, a partir disso, se esse processo de abreviação da comunicação poderia ser observado em interações de bebês com seus pares de idade.

Como indica análise da revisão de Costa (2008), tal processo não vem sendo estudado na interação entre coetâneos e sim apenas na relação do bebê com o adulto, particularmente a mãe. Essa questão da interação de pares de bebês é pouco investigada no campo, inclusive por haver posicionamentos que negam a possibilidade de sua ocorrência. Como afirmam Brownell, Ramani e Zerwas (2006), a coordenação de crianças de um ano de idade parece ser mais coincidência. Para esses autores, a criança somente se tornaria um verdadeiro parceiro social depois do segundo e terceiro anos de vida, ligado à crescente compreensão social.

Porém, essas questões têm sido consideradas como devendo ser revistas. Particularmente por que, devido ao crescente ingresso da mulher no mercado de trabalho, com a necessidade de compartilhamento do cuidado e da educação da criança pequena, muitos bebês passaram a frequentar instituições de educação coletiva. Nesse contexto, em que a relação adulto-criança é mais baixa do que no ambiente doméstico, e a depender da organização do ambiente, o outro bebê passou a ser o parceiro mais frequente, havendo maior contato entre os pares de idade. Tal situação impôs a necessidade de construção de conhecimento sobre essa nova condição no campo social, inclusive por que se articula com indícios positivos de ocorrência de interação entre os bebês, com a necessidade de se compreender o que acontece nesse encontro. Há somente o encontro e o interesse? Ou há também comunicação entre os bebês? E, em caso de comunicação, a criança desenvolveria formas abreviadas, como observado na relação com o adulto? Deste modo, o objetivo foi investigar se ocorre abreviação da comunicação, na interação de bebês com coetâneos. E, em caso afirmativo, investigar como se dá o processo.

\section{Método}

A perspectiva teórico-metodológica que orientou a coleta e a análise de dados é a Rede de Significações (RedSig) (Rossetti-Ferreira, Amorim \& Silva, 2000, 2004). Esta se constitui como uma ferramenta para a compreensão e investigação dos processos do desenvolvimento humano. Estes, de acordo com a perspectiva, se dão através de processos de coconstrução com o outro, durante todo o ciclo vital, nas e através das múltiplas interações estabelecidas, em contextos social e culturalmente organizados. De forma situada e contextualizada, pessoas e contextos encontram-se inseridos em, impregnados e transformados por uma matriz sócio-histórica composta por elementos sociais, econômicos, políticos, históricos e culturais, em constituição recíproca (Amorim \& Rossetti-Ferreira, 2004).

Na presente pesquisa, o estudo da abreviação se fez para apreender encontros, relações e comunicações do bebê com outros (bebês), em contexto histórico-cultural específico (creche).

Para isso, estruturou-se o trabalho através da condução de estudos de caso múltiplos. O estudo de caso é usado como estratégia de pesquisa, quando a pergunta que a respalda envolve "como" e "por que" determinado evento acontece (Yin, 2005; Pozzebon \& Freitas, 1998). Segundo estes autores, o estudo de caso envolve, ainda, a investigação de fenômenos complexos, em que se busca preservar as características dos acontecimentos da vida real, sem 
possibilidade de controlar eventos comportamentais. Nesta pesquisa, tais eventos implicam situações de encontro e interação de bebês, no cotidiano de uma creche.

Como Yin (2005) ressalta, a meta não é generalizar estatisticamente os dados através da amostragem, mas a partir da análise desdobrar teorias e proposições. A análise não caminha assim no sentido de realizar restrições individuais, mas determinar se as proposições de uma teoria se reiteram ou outras explanações devem ser buscadas.

No presente estudo, definiu-se pela condução de estudos de caso múltiplo. Para isso, o projeto foi apresentado ao e aprovado pelo Comitê de Ética e Pesquisa (CEP), a pesquisa tendo tido o compromisso de preservar os aspectos éticos relacionados aos sujeitos participantes investigados, de acordo com as normas da Resolução 196/96 e da atual Resolução 466/12, do Conselho Nacional de Saúde.

O estudo de caso se deu a partir da investigação dos processos comunicativos de um casal de gêmeos entre si e deles com outros parceiros de idade. Para isso, foram utilizadas gravações do Banco de Dados do Projeto Integrado Processos de adaptação de bebês à creche, o qual acompanhou o ingresso e a frequência de 21 bebês (4-14 meses de idade) a uma creche universitária. Para este estudo, foram utilizadas gravações em vídeo do berçário, realizadas durante os três primeiros meses do período em que os bebês estavam freqüentando a creche e que resultaram em arquivo de 75 horas de gravação.

Os sujeitos-pivôs desta pesquisa foram o casal de gêmeos, Armando e Isa ${ }^{1}$, de $11 \mathrm{~m} 21 \mathrm{~d}$, no ingresso à creche. Além deles, outras quatro crianças foram selecionadas como parceiros preferenciais. Para a seleção dos parceiros, utilizou-se como critério: quantidade suficiente de episódios interativos entre as crianças, os quais deveriam estar presentes ao longo do tempo de modo a permitir uma análise deste período. Ainda, os episódios deveriam ter qualidade de imagem que evidenciassem sua complexidade para uma análise refinada e detalhada.

A partir desses critérios, analisou-se todas as 75 horas de gravação, os parceiros preferenciais sendo selecionados. Os parceiros de Isa são Gilson (12m5d) e Iraíades (9m15d). Já os de Armando são Gilson (12m5d) e Reis (14m25d). Importante ressaltar que Isa e Armando são considerados parceiros preferenciais entre si, não só por serem irmãos e apresentarem história de vida comum, como também por se enquadrarem nos critérios propostos.

Do total de horas de gravação, foram selecionadas todas as cenas em que Isa e Armando apareceram. Estas cenas foram editadas seguindo o tempo cronológico e compondo bloco único de imagens. Essas cenas foram vistas e, a partir delas, foram identificados os episódios interativos dos gêmeos entre si e deles com seus parceiros preferenciais. As cenas foram separadas segundo o parceiro de interação em subblocos

Deste conjunto, foram selecionados os episódios em que se apresentavam, com clareza, processos de comunicação entre as crianças. Todos os episódios foram transcritos microgeneticamente, sendo construído um roteiro estruturado cronologicamente e com detalhamento, destacando local

1 Todos os nomes aqui utilizados são fictícios. onde estavam, os bebês e as outras pessoas nas cenas, as atividades realizadas, as comunicações verbais e nãoverbais; ainda, a concomitância com que diferentes eventos ocorreram, a sequência de cada um e, se e como um afetava o outro (Branningan \& Humphries, 1981). Esse tipo de transcrição permitiu acompanhar as interações estabelecidas dos coetâneos, para depois dar seguimento à análise dos episódios.

Esta se deu através de análise microgenética, constituída pela elaboração de uma microhistória, interpretável sob a perspectiva semiótica em que pesam as condições amplas da cultura e da história (Góes, 2000). Esta forma de análise é orientada aos detalhes e ao recorte de episódios interativos, permitindo maior visibilidade da complexidade das ações socialmente direcionadas. Nesse sentido, buscou-se apreender, através dos gestos e olhares, as transformações nas relações. Dos vários episódios transcritos, alguns foram selecionados para serem aqui apresentados.

\section{Resultados e Discussão}

Do conjunto de episódios das crianças, selecionou-se três duplas de episódios: dois entre Isa-Armando; dois entre Armando-Gilson; e, dois entre Isa- Iraíades (Costa, 2008). Os episódios serão apresentados, após o que será feita a discussão.

Episódio 01 entre Armando e Isa (11m21d): “Um brinquedo novo para dois bebês."

Este ocorreu no primeiro dia em que passaram a frequentar a creche. Duração: 15 segundos. Além de Armando e Isa, Sara (mãe) e Milena (educadora) participam da cena.

A mãe e educadora estão em pé e conversam. Sara segura Isa (identificada pela no colo e Milena segura Armando (identificado pelo $\mathbf{\square}$ ). A mãe coloca Isa em pé no chão, segurando-a pelos braços. Milena coloca Armando sentado no chão.

Nesse movimento, os pés de Armando provocam o deslocamento de cachorrinho com rodas em direção a Isa, que por fim também é colocada sentada no chão. Isa olha para o cachorrinho e leva o braço esquerdo na direção do mesmo, tocando-o (Figura 01), enquanto Milena e Sara se afastam dali. Isa as segue com o olhar, ao mesmo tempo em que Armando estende os braços e pega o cachorro. Isa olha na direção do irmão, leva os braços em direção ao cachorro e este cai no chão. Milena que estava próxima pega um cachorrinho semelhante e mostra à Isa, mas ela continua focada no primeiro. A educadora entrega o segundo cachorrinho, colocando-o entre os irmãos e depois se afasta. Isa toca o primeiro cachorrinho e Armando toca o segundo cachorrinho (Figura 02).

Isa olha para frente, vira de lado e engatinha em sentido oposto ao do irmão (e a gravação é interrompida).

Episódio 02 entre Armando e Isa (11m21d): "Peguei primeiro!"

Este ocorreu 14 dias após o episódio anterior. Duração: 55 segundos. Além de Armando e Isa, participam Sara (mãe dos gêmeos) e Mirtes (educadora).

Isa (identificada pela está sentada no colchão. Sara está em pé, atrás da filha. Isa olha para baixo e com a mão direita 


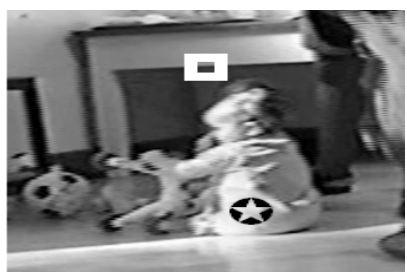

Figura 01. Isa e Armando Ep. 01

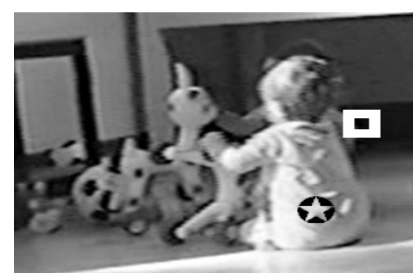

Figura 02. Isa e Armando Ep. 01

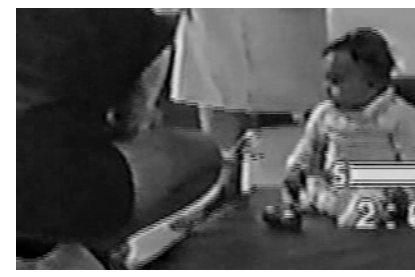

Figura 03. Isa e Armando Ep. 02 toca um cilindro à sua frente. Mirtes, que tinha Armando (identificado pelo $\mathbf{\square}$ ) no colo, coloca-o no chão, próximo à irmã. Armando olha e também toca o cilindro. Isa olha para o rosto e para a mão de Armando e, depois, para o cilindro (Figura 03). Enquanto isso, Armando pega o cilindro. Isa olha para o rosto do irmão e, depois, na direção da mãe. Ela volta a olhar para Armando e chora. Após alguns segundos, ela para o choro, vira o corpo na direção de Armando e leva a mão na direção dele, enquanto o olha.

Ela está com a palma da mão virada para baixo, permanecendo estendida na direção do irmão. Isa olha para Armando e para o cilindro; pára de chorar. Então, ela estende a mão esquerda, com a palma da mão virada para cima, permanecendo estendida na direção do irmão. Isa olha as suas próprias mãos e depois o rosto do irmão. Armando segura o cilindro com as duas mãos (Figura 04). Isa apóia a mão esquerda no colchão e leva novamente a mão direita na direção de Armando, com a palma virada para baixo, tocando o cilindro. Sem conseguir pegá-lo, chora e olha na direção da mãe e de Mirtes. Armando olha para o outro lado. A educadora diz: “Oi, Isa?!". Isa pára de chorar e volta a olhar para Armando. Novamente, ela fica em posição de engatinhar. Ela estende o braço direito na direção de Armando, com a palma da mão virada para baixo e levemente curvada. Toca o cilindro e a perna do irmão (Figura 05).

Ambos se olham fixamente. Sem sucesso, Isa se senta, franze a testa e chora. Ela olha para o irmão e para frente. Armando olha para a irmã. Isa pára de chorar. Isa olha para Sara e para Armando, voltando a chorar. A mãe olha aos filhos e ao redor, enquanto Isa continua chorando. Sara se abaixa, pega um objeto e o oferece para Isa, dizendo: "Aqui outro, oh!". Armando olha para a mão de Sara. Isa olha na direção de Mirtes, depois olha para baixo e vê a mão da mãe.

No primeiro episódio, Armando e Isa estavam tendo o primeiro contato com o ambiente da creche. Neste dia, ambos foram colocados juntos e, neste episódio, interagiram desde os primeiros instantes. Sua interação abarcou a atenção e o interesse por um mesmo objeto (cachorrinho), ambos buscando pegá-lo. Nisso, desdobram-se comunicações e negociações entre eles. $\mathrm{O}$ objeto em questão parece ser desconhecido, o que poderia representar um elemento novo a ser explorado e, por isso, alvo de disputas. Independentemente da motivação, a interação se efetiva com a intermediação de um objeto (como descrito por Lyra, 2000). A interação abarcou ainda características como discutidas por Carvalho et al. (1996), em que apesar de as crianças não realizarem uma atividade propriamente conjunta, o comportamento de cada uma delas se mostrava regulado pelo comportamento da outra.

As negociações envolveram uma série de comportamentos, gestos e posturas por parte de Isa e Armando. No caso, logo que é colocado no chão, Armando busca pelo cachorrinho que está sendo manipulado pela irmã. Ele realiza essa ação de forma rápida, sem haver trocas de olhares, demonstrando a ausência de uma negociação extensa acerca do objeto disputado - parece aqui já haver uma abreviação dos comportamentos comunicativos.

A educadora, buscando entreter as duas crianças, inclui novo elemento - segundo cachorro - e, por meio deste, interrompe-se por alguns instantes as negociações em curso entre Isa e Armando. Nesse momento, ela configura uma situação poliádica, de atenção conjunta (Tomasello, 2003; Bruner, 2007), na qual a atenção dos gêmeos se desloca para a educadora e a um quarto elemento - outro cachorrinho. Com o afastamento da educadora, a atenção dos dois aos objetos é retomada. Nesse processo, percebe-se que a comunicação da díade Isa-Armando possui características abreviadas, a regulação da comunicação e das ações sendo recíproca, fazendo-se de maneira rápida e fácil.

No segundo episódio, Isa é colocada sobre um colchão e ela vê um objeto (o cilindro) à sua frente. Armando é colocado ao seu lado e, imediatamente, ele o pega. Novamente, a atenção conjunta discutida por Tomasello (2003) e Bruner (2007) se mostra aqui evidenciada. Importante notar que Isa

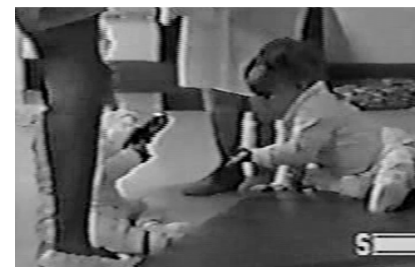

Figura 04. Isa e Armando Ep. 02

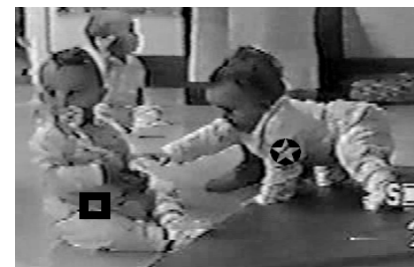

Figura 05. Isa e Armando Ep. 02

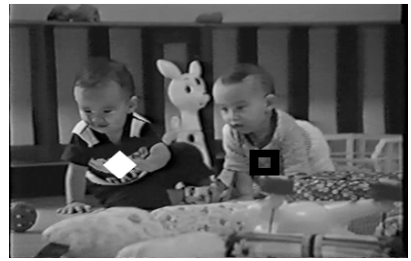

Figura 06. Armando e Gilson Ep. 03 


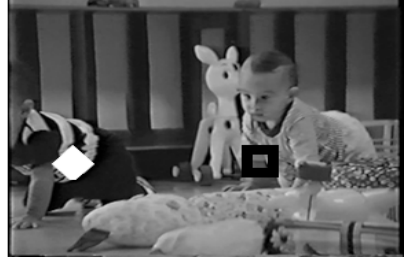

Figura 07. Armando e Gilson Ep. 03

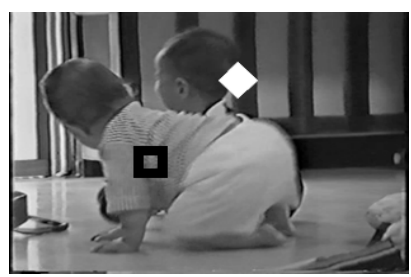

Figura 08. Armando e Gilson Ep. 03

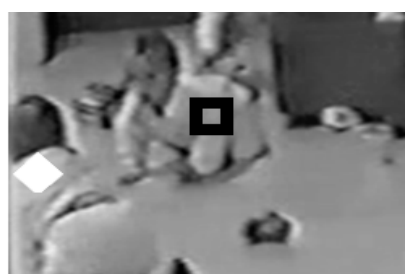

Figura 09. Armando e Gilson Ep. 04 vê a mão do irmão se aproximando do objeto e não intervém, em um momento inicial. Depois que o irmão pega o objeto é que ela tenta retomá-lo. Contudo, ele não cede, ainda que ela chore por três vezes.

$\mathrm{Na}$ interação, ao buscar resgatar o cilindro, Isa utiliza diferentes recursos comunicativos. Um primeiro é o choro recurso muito utilizado por Isa e que representa importante recurso de vocalização em bebês (Elmôr, 2009). Outro recurso é o repetido uso corporal. Importante perceber, no entanto que esse uso já é dotado de sentido cultural: no primeiro momento, ela busca o cilindro tentando pegá-lo, tomá-lo do outro (mão virada para baixo). Depois, ela estica a mão no sentido de pedir /receber (palma da mão aberta virada para cima). Por fim, Isa novamente tenta pegar o objeto (palma da mão virada para baixo). Demonstra, assim, fazer uso de recursos comunicativos carregados de significados (Amorim \& Rossetti-Ferreira, 2008; Correia, 2009; Vallotton, 2011).

Por outro lado, o irmão apreende a intencionalidade (Tomasello, Carpenter \& Liszkowski, 2007; Sinha \& Rodriguez, 2008) de Isa (interesse por obter o objeto) e, através da comunicação corporal (segura objeto com as duas mãos, virando o corpo até quase ficar de costas para ela), desviando-se da ação da irmã. Apesar da idade e das competências comunicativas, no diálogo mudo (ScorsoliniComin \& Amorim, 2010), as duas crianças antecipam a intencionalidade do outro e se posicionam em relação a isso.

A presença da mãe influencia o desfecho e evidencia a diferença na construção e desenvolvimento das relações. Nesse sentido, vê-se que Armando não cede ao choro de Isa. Em contrapartida, quando Isa chora olhando para a mãe, esta olha para os filhos e procura por um cilindro semelhante para dar a Isa, de modo a resolver o impasse. A atenção da mãe para as ações dos filhos também parece indicar que a relação entre ela e os filhos está abreviada, pela prontidão com que procura e entrega objeto semelhante (Lyra, 2000).

Episódio 03 de Armando (11m21d) e Gilson (12m5d): "Para onde vai a bola?"
Este ocorreu quatro dias após o ingresso dos gêmeos à creche. Duração: 28 segundos.

Armando (identificado pelo $\mathbf{D}$ ) segura com a mão direita uma pequena bola. Gilson (identificado pelo $\$$ ) está sentado ao lado de Armando e segura e olha objeto de plástico e, a seguir, olha para Armando.

Armando gira a bola na mão e, nesse movimento, ela cai, parando à sua frente. Armando pega a bola e abre a mão. Novamente, ela cai, deslocando-se para mais longe. Armando a vê e, imediatamente, engatinha na direção da mesma. Gilson - que está ao seu lado - olha para a bola, enquanto segura um círculo. Ao vê-la, Gilson arregala os olhos, solta o objeto, sorri e coloca-se na posição de engatinhar (Figura 06). Armando vê Gilson à sua frente e ergue as sobrancelhas. Gilson, sem parecer ver Armando, engatinha rapidamente em direção à bola, apresentando leve sorriso. Parado na posição de engatinhar, Armando olha alternadamente para Gilson e à bola (Figura 07 ).

Armando passa, então, a engatinhar muito rapidamente. Quando se aproxima da bola, Gilson já a tem nas mãos. Armando pára ao lado de Gilson, olhando alternadamente à bola e ao rosto de Gilson, com os olhos arregalados (Figura 08). Armando engatinha à frente de Gilson. Gilson olha para Armando, que se aproxima. Gilson vira o corpo para a direção oposta à de Armando. Este engatinha ao lado de Gilson, indo na mesma direção, alternando o olhar entre a bola e o rosto de Gilson.

Episódio 04 de Armando (11m21d) e Gilson (12m5d): "Esta caixa é minha!"

Este ocorreu 47 dias após ingresso dos gêmeos à creche. Duração: 28 segundos.

Gilson (identificado pelo $\bullet$ ) está próximo a Armando (identificado pelo $\mathbf{\square}$ ), que engatinha para frente e olha na direção de Armando.

Este se coloca na posição de engatinhar, olha para Gilson e engatinha em sua direção (Figura 09). Ambos ficam frente a frente e se olham por alguns segundos. Armando e Gilson

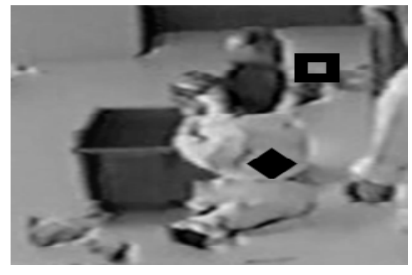

Figura 10. Armando e Gilson Ep. 04

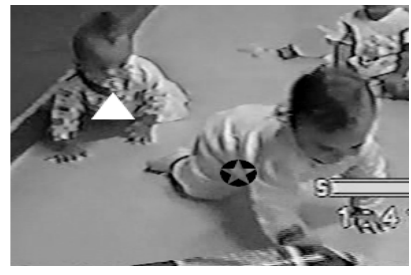

Figura 11. Isa e Iraíades Ep. 05

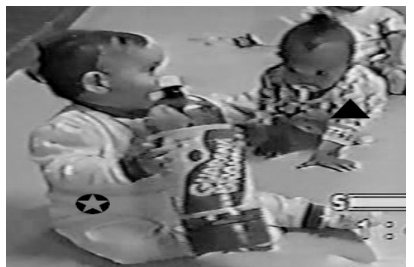

Figura 12. Isa e Iraíades Ep. 05 


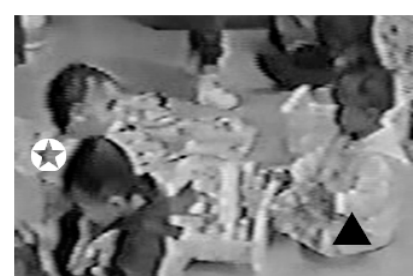

Figura 13. Isa e Iraíades. Ep. 06

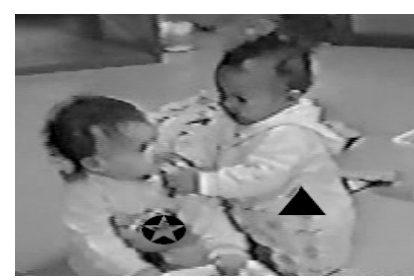

Figura 14. Isa e Iraíades. Ep. 06

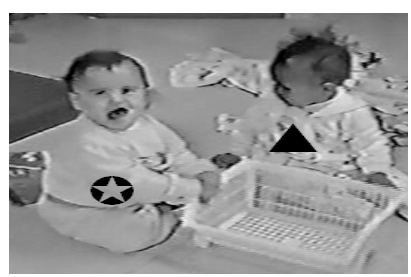

Figura 15. Isa e Iraíades. Ep. 06 passam, então, a engatinhar na mesma direção - de uma caixa vermelha que contém brinquedos. Gilson se senta e estica os braços na direção da caixa. Armando se senta ao lado de Gilson. Lado a lado, puxam a caixa para perto de si. Armando se debruça sobre a caixa. Gilson olha para Armando. Armando empurra a caixa contra o chão e a parte em que Gilson se apóia, levanta. Gilson olha para Armando e Armando para Gilson por alguns segundos. Eles continuam a se olhar e soltam a caixa.

O terceiro episódio representa a primeira cena registrada de interação de Armando e Gilson, tendo ocorrido na primeira semana, quando Armando passou a frequentar a creche. No caso, Armando manipula uma bola, que cai de sua mão e rola à frente de Gilson. Estabelecida a atenção conjunta, é possível identificar a intencionalidade (Tomasello, 2003, Sinha \& Rodriguez, 2008) de Armando em pegar a bola de Gilson. Armando olha alternadamente entre objeto e parceiro, engatinhando em velocidade acelerada atrás dela. Contudo, Gilson chega e pega a bola antes dele. Armando segue os movimentos de Gilson e, aparentemente, busca resgatar a bola, sem pegá-la prontamente, como faz usualmente com a irmã, evidenciando formas diferenciadas de negociar a posse de objetos com os diferentes parceiros. Há uma negociação pelo olhar (Belini \& Fernandes, 2007), o qual se alterna entre bola e rosto, sempre reticente. Este padrão se mantém ao longo de todo episódio, de modo que Armando segue Gilson com os olhos e o corpo, observando as ações e reações do outro. No processo, há regulação mútua, as ações de Armando estando intrinsecamente ligadas às de Gilson, sendo a recíproca também verdadeira, já que este segura firme o objeto, protegendo-o com o próprio corpo (Carvalho et al., 1996 ).

No quarto episódio, a relação evidencia abreviação das ações e da comunicação entre os dois, como discutido por Lyra (2000). Armando e Gilson se encontram e se olham nos olhos longamente, sem emitirem balbucio ou emitirem outra expressão facial. Após isso, ambos engatinham, conjuntamente, em direção à mesma caixa de brinquedos e se olham antes de chegarem a ela. Armando se debruça sobre a caixa, enquanto Gilson se aproxima dela. Em determinado momento, Armando puxa a caixa para si, parecendo que eles disputam a caixa. A partir deste momento, Gilson e ele se olham intensamente.

Este olhar parece estar repleto de significados, na medida em que, a partir daí, não parece haver mais disputa pela caixa, mas seu compartilhamento. O direcionamento do olhar se mostra como importante elemento comunicativo, representando forma de transmitir sinais socialmente relevantes (Gerbelli, 2006; Guimarães, 2008; Belini \& Fernandes, 2007), aqui verificado na relação entre bebês.

$\mathrm{Na}$ análise dos dois episódios, verifica-se a abreviação (Lyra, 2000), em que os recursos utilizados na negociação passam a ocorrer de forma rápida. Destaca-se aqui o fato de que a díade utilizou o olhar como recurso comunicativo predominante. Mais ainda, indica-se a ocorrência do processo de abreviação como descrito por Carvalho, ImpérioHamburger e Pedrosa (1996), no qual uma informação adquiriu significação e esta persistiu em outros momentos, diferenciando-se de uma simples negociação.

Episódio 05 de Isa (11m21d) e Iraíades (9m15d): Olha o que ela faz com o brinquedo!

Este ocorreu oito dias após o ingresso dos gêmeos à creche. Duração: 65 segundos.

Isa (identificada pela está sentada no chão, segurando uma garrafa pet. Iraíades está em posição de engatinhar em cima do colchão. Isa segura a garrafa pela tampa, com as duas mãos. Depois, com os dedos, ela toca toda a extensão da garrafa. Isa olha ao seu redor e vê Iraíades (identificada pelo $\boldsymbol{\Delta}$ ).

Esta última engatinha de costas para fora do colchão. Isa inclina a garrafa para o lado direito, segura a garrafa pela tampa e olha na direção da porta. Por várias vezes, Isa mexe os braços e a garrafa. Atrás de Isa, Iraíades se apóia no colchão. Enquanto isso, Isa olha para a garrafa, abaixa o braço e a garrafa cai no chão, rolando para frente. Isa se inclina. Nesse mesmo instante, Iraíades olha para a garrafa. Isa se coloca em posição de engatinhar e olha para a garrafa. Iraíades e Isa engatinham na direção da garrafa (Figura 11), apesar de que Iraíades olha na direção da porta. Após, Iraíades olha para Isa e para a garrafa.

Isa toca a garrafa, segura-a com as duas mãos, sorri e olha para a mesma. Iraíades olha para o chão, depois para a garrafa e se senta. Isa olha Iraíades (Figura 12). Isa aproxima a tampa da garrafa da boca. Iraíades se coloca na posição de engatinhar. Isa balança o corpo para frente e para trás. Iraíades engatinha para o lado oposto de Isa.

Episódio 06 de Isa (11m21d) e Iraíades (9m15d): "Também quero segurar esta caixa!"

Este ocorreu 86 dias após o ingresso dos gêmeos à creche. Duração 1 minuto.

Isa (identificada pela ) segura uma caixa branca de plástico e a coloca à sua frente. Iraíades Iraíades (identificada pelo $\mathbf{\Delta})$.

está sentada ao seu lado e segura a borda da caixa com as duas mãos. Isa empurra e puxa a caixa, enquanto Iraíades retira uma revista de dentro dela. Iraíades inclina o corpo para frente, olhando para o rosto de Isa. Depois, ergue os braços na 
direção de Isa, na altura dos ombros, olhando-a. Iraíades se inclina mais, toca o ombro esquerdo de Isa e puxa levemente sua blusa. Elas se olham nos olhos. Isa inclina o corpo para frente e olha ao lado esquerdo (Figura 13).

Ela olha para Iraíades e solta a caixa. Depois, Iraíades inclina mais o corpo, apóia-se nos joelhos e aproxima seu rosto do de Isa. Isa olha para as mãos de Iraíades e impulsiona seu corpo para trás. Isa vira o corpo na direção de Iraíades, enquanto segura a caixa e olha para as mãos de Iraíades (Figura 14).

Esta olha ao chão e se apóia em Isa, erguendo mais o corpo, até ficar apoiada em seus joelhos. Isa se apóia na caixa, mas esta se desloca. Ela apóia os braços no chão, em posição de engatinhar. Enquanto isso, Iraíades olha atentamente ao rosto de Isa. Esta se senta e inclina seu corpo para trás. Iraíades solta o braço esquerdo de Isa e fica de joelhos. Ambas se olham fixamente nos olhos. Iraíades perde o equilíbrio e fica na posição de engatinhar.

Isa olha para Iraíades e, em seguida, para onde Iraíades estava olhando. Arregala os olhos. Rapidamente, coloca-se na posição de engatinhar, engatinha e pára ao lado de Iraíades. Neste momento, ambas tocam novamente a caixa. Isa segura a caixa com as duas mãos, olha para frente, abre bastante a boca e grita forte "Aaaaaa!", enquanto puxa a caixa para próximo de seu corpo. Iraíades olha para as mãos de Isa e, depois, para seu rosto (Figura 15).

Isa contorce a boca e fecha levemente os olhos. Ela ergue e abaixa a caixa três vezes. Iraíades olha para Isa e para frente. Isa ergue e solta a caixa no chão mais três vezes, fazendo barulho. Iraíades olha para a caixa. Isa puxa a caixa para próximo de si e coloca a caixa sobre sua perna direita. Iraíades olha para o lado, vira o corpo em direção contrária a Isa e olha na direção de algumas revistas. Isa engatinha segurando a caixa. Iraíades vira o corpo na direção das revistas e segura uma revista com as duas mãos.

No quinto episódio, há interação entre as duas crianças, sendo o comportamento de Iraíades regulado pelo de Isa e vice-versa. Há atenção conjunta (Tomasello, Carpenter, \& Liszkowski, 2007), porém, não há ocorrência de estabelecimento da atenção, como proposto por Lyra (2007). Há a eleição de um elemento comum (garrafa), tanto por Isa quanto Iraíades. E, quando a garrafa cai da mão de Isa, ambas engatinham em sua direção. Os recursos utilizados por ambas são sutis, com base principalmente no olhar que se efetiva de modo muito breve.

Já no sexto episódio, há atenção conjunta, com direcionamento das duas a um objeto. Ainda, ambas parecem apreender a intencionalidade da outra de tê-lo (Sinha \& Rodriguez, 2008), configurando-se uma disputa com negociação. Nesta, novas possibilidades de ação e comunicação se configuram, com a utilização de recursos comunicativos que parecem ter se complexificado em duração e qualidade.

Inicialmente, a posse é negociada pela aproximação física da caixa. Posteriormente, pela aproximação física da díade. No caso, Isa parece defender tanto a posse da caixa, quanto a si mesma dos movimentos de Iraíades, já que Iraíades se apóia e se aproxima de seu rosto, sustentando-se em sua roupa e ombros. Aparentemente, a própria dificuldade motora de Iraíades acaba por promover, estender e aprofundar a interação das duas crianças (Franchi e Vasconcelos, et al, 2003).

Isa demonstra ficar incomodada, vocalizando e fazendo expressões de irritação. No decorrer do episódio, o modo como as duas se olham passa a materializar diferentes significações. Inicialmente, os olhares parecem identificar e acompanhar as ações da outra, como que monitorando seu comportamento. No decorrer, olhar de Iraíades parece acompanhar Isa, tanto que se aproxima muito dela. O olhar de Isa para Iraíades é representativo de que ela a solte. Como Iraíades permanece segurando sua blusa e se apoiando nela, aquela grita.

De forma geral, percebe-se que o tipo de relação entre Isa e Iraíades apresenta diferenças entre o início e decorrer do processo. As interações se complexificaram e passaram a envolver negociações intensas e com indicações de que poderiam se configurar como o processo de abreviação, tanto descrito por Lyra (2000), quanto por Carvalho, ImpérioHamburger e Pedrosa (1996).

\section{Considerações Finais}

Falar de interação de bebês com seus coetâneos representa um trabalho que, de modo geral, se confronta com conceitos de alguma maneira mais cristalizados na área. Tradicionalmente, entende-se que o bebê interage com os adultos, particularmente com a mãe, com quem aprende e desenvolve suas habilidades iniciais de linguagem e cognitivas (Bowlby, 1969; Borges \& Salomão, 2003; Mendes \& Seidl Moura, 2009). Interações e comunicações com outros parceiros são pouco investigados, em especial dos bebês com seus pares de idade. Tal lacuna se dá, particularmente, por não se entender que tal processo se efetive nessa faixa etária, como discutem Brownell, Ramani e Zerwas (2006).

Tais afirmações, entretanto, mostram marcas de uma psicologia que frisa concepções de interação ligadas a fazer algo junto e carregando características presentes em crianças mais velhas, tendo como base uma perspectiva adultocêntrica. Porém, a despeito dessas posições, quando se analisa cenas de videogravação de bebês que compartilham o espaço em instituições do tipo creche, pode-se ter acesso a situações inusitadas de interações de pares de bebês, em que a comunicação, a negociação e a atribuição de significações estão presentes.

Nos dados empíricos aqui analisados, em relação aos aspectos da interação entre os bebês, verificou-se que a maior parte destes envolviam a presença de objetos. Para os adultos, esses movimentos parecem representar disputa, o que os leva a dar objetos semelhantes a cada uma das crianças. No entanto, análise evidencia que os objetos constituem sim atrativos, mas não se pode dizer que o comportamento seja regulado unicamente pela atração pelos objetos em si. Ainda mais quando, ao manipular estes objetos - mover, chupar, jogar, chacoalhar, etc., - a criança lhes dá vida/movimento. A hipótese é, portanto, de que atração se dá pelo complexo bebê-objeto (Amorim, Anjos \& Rossetti-Ferreira, 2012). Com isso, a atenção e o interesse dos bebês junto aos mesmos fazem com que os próprios bebês iniciem o direcionamento 
ao par de idade, chegando até mesmo a haver partilha do objeto (como no episódio 4 entre Gilson e Armando).

À análise, verificou-se ainda a ocorrência de comunicação entre as crianças, com o uso variado de recursos, tanto pelo olhar, como vocalizações, expressões faciais, gestos e movimentos corporais. Através desses, os bebês expressavam significados para o outro (dentre eles de disputa pela posse), os recursos já se mostrando carregados de significados culturais (Fogel, 1992 Amorim \& Rossetti-Ferreira, 2008; Vallotton, 2011), como evidenciados nos gestos de "dar" e "tomar" o cilindro no segundo episódio.

Nos processos interativos e comunicativos, evidenciouse a ocorrência do estabelecimento da atenção conjunta (Tomasello, 2003) entre os bebês. Essa habilidade - discutida usualmente nas interações com o adulto - foi verificada na interação do bebê com seu par de idade. Ainda, apareceu não só o estabelecimento de articulação triádica (bebêbebê-objeto), como poliádica (bebê-bebê-educadoraobjeto1-objeto2), através do que permitiu a identificação de intencionalidade no comportamento do parceiro (Tomasello, Carpenter \& Liszkowski, 2007; Sinha \& Rodriguez, 2008).

Essas particularidades aparentemente foram coconstruídas ao longo do tempo de convivência e em função de como os recursos utilizados mostraram-se efetivos (ou não) nas relações, dentro daquele contexto da creche. $\mathrm{O}$ modo como estes recursos passaram a ser desenvolvidos, utilizados, apreendidos, (in)utilizados, etc, apresentaram as possibilidades e/ ou restrições ao percurso desta própria utilização.

Especificamente em relação à abreviação, vale frisar que os estudos de Lyra (2000) tratam de bebês até o nono, décimo mês de vida; e, que, no presente estudo, as crianças são um pouco mais velhas, tendo 11-12 meses de idade. Apesar de que a diferença de idade dos sujeitos aqui analisados é pequena em relação aos de Lyra - em torno de dois meses -, o processo pode ser verificado na relação dos pares, mesmo em condições em que as crianças eram pouco próximas em termos relacionais (à exceção dos gêmeos).

Os processos de abreviação, portanto, foram entendidos como se dando nessas relações. No desdobrar das interações, as crianças passaram a não ter mais uma observação prolongada do outro, nem uma negociação tão cuidadosa em relação à tomada de objeto ou à participação de atividade junto ao outro. Ainda, gradativamente, os bebês passaram a não ter nem mesmo uma observação mais criteriosa da reação do outro, tão presente nos primeiros eventos interativos (Amorim, Anjos \& Rossetti-Ferreira, 2012).

Ainda, a abreviação se deu de forma diferente em cada díade, a depender do parceiro e das formas de relações estabelecidas, demonstrando a complexidade deste processo já no final do primeiro ano de vida. As características da relação evidenciaram trocas rápidas, mútuas e fáceis. Os olhares para o objeto e as vocalizações foram mais utilizados por Isa nas negociações com o irmão. Em relação a Iraíades, o olhar predominou como recurso, o olhar não parecendo se polarizar nem no objeto nem no parceiro de interação. No caso de Armando, o olhar quase não era utilizado nas negociações com a irmã. Em relação a Gilson, porém, o olhar assume um caráter de cumplicidade. Com Iraíades, emerge a vocalização de Isa que não apareceu nos outros episódios analisados.

Concluindo, entende-se que, partindo de novas condições sociais (com o ingresso crescente da mulher no mercado de trabalho e o compartilhamento da educação com instituições; e, a necessidade de compreender os processos por que passam as crianças pequenas nesse novo contexto de educação, em que o parceiro de idade é o mais frequente) e de estudos empíricos que trazem indícios de interação de bebês com seus pares, buscou-se verificar se ocorria comunicação e abreviação da comunicação nessas relações. Os dados empíricos analisados confirmaram a ocorrência desses processos.

Entende-se que tal estudo se reveste de importância prática na construção desse conhecimento pelas implicações nos cuidados das crianças, particularmente em ambientes de educação coletiva. Ainda, reveste-se de importância teórica, já que, nessa perspectiva, discute-se o papel fundante do outro social no desenvolvimento do bebê, mostrando necessário investigar o papel na ontogênese quando este outro é também um outro bebê. $\mathrm{O}$ presente estudo aponta positivamente à ocorrência de abreviação da comunicação, nas crianças e contexto estudado. Novos estudos deverão ser conduzidos, para se entender como se dá o papel de recorte/destaque na comunicação entre as crianças dessa faixa etária; como esse recorte se faz já com a construção de significados em tão tenra idade; e, ainda, as implicações desses processos na ontogênese da criança.

\section{Referências}

Amorim, K. S. (2010). Proximidade / distanciamento: a intercorporeidade e a mútua constituição eu-outro-ambiente. In M.I.S. Leme \& P.S. Oliveira (Orgs.) Proximidade e distanciamento: superando dicotomias (pp. 91-118). São Paulo: Casa do Psicólogo.

Amorim, K. S., Anjos, A. M., \& Rossetti-Ferreira, M.C. (2012). Processos interativos de bebês em creche. Psicologia: Reflexão e Crítica, 25(2), 1-12.

Amorim, K. S., \& Rossetti-Ferreira, M. C. (2004). A matriz sóciohistórica. In M.C. Rossetti-Ferreira, K.S. Amorim, A.P.S. Silva \& A.M.A. Carvalho (Orgs.), Rede de Significações e o estudo do desenvolvimento humano (p. 93-112). Rio Grande do Sul: Artmed.

Amorim, K. S., \& Rossetti-Ferreira, M. C. (2008). Dialogismo e a investigação de processos desenvolvimentais humanos. Paidéia, 18(40), 235-250.

Amorim, K. S., \& Rossetti-Ferreira, M. C. (2008). In M.C. RossettiFerreira, K.S. Amorim, A.P.S. Silva \& A.M.A. Carvalho (Orgs.), Rede de Significações e o estudo do desenvolvimento humano (p. 93-112). Rio Grande do Sul: Artmed.

Belini, A.E.G., \& Fernandes, F.D.R. (2007). Olhar de bebês em desenvolvimento típico: correlações longitudinais encontradas. Revista Sociedade Brasileira Fonoaudilogia, 12 (3), 165-173.

Borges, L.C., \& Salomão, N.M.R. (2003). Aquisição da linguagem: considerações da perspectiva da interação social. Psicologia Reflexão e Crítica, 16(2), 327-336.

Bowlby, J. (1969). Attachment and Loss. Vol.1: Attachment. New York: Basic Books. 
Branningan, C. R., \& Humphries, D. A. (1981). Comportamento Não-Verbal Humano, Um Meio de Comunicação. In N. Blurton-Jones (Org), Estudos Etológicos do Comportamento da criança. São Paulo: Biblioteca Pioneira de Ciências Sociais.

Brownell, C.A., Ramani, G.B., \& Zerwas, S. (2006). Becoming a social partner with peers: Cooperation and social understanding in one- and two-year-olds. Child Development, 77(4), 803 821.

Bruner, J. (1997). Atos de significação. Porto Alegre: Artes Médicas.

Bruner, J. (2007). Como as crianças aprendem a falar. Lisboa: Instituto Piaget.

Carvalho, A.M.A. (1998). Etologia e comportamento social. In L. Souza, M.F.Q. Freitas, \& M.M.P. Rodrigues (Orgs.), Psicologia - Reflexões (im)pertinentes (pp. 195-224). São Paulo: Casa do Psicólogo.

Carvalho, A.M.A., Império-Hamburger, A., Pedrosa, M.I. (1996). Interação, regulação e correlação no contexto do desenvolvimento humano: discussão conceitual e exemplos empíricos. Publicações, IFUSP/P 1196, 1-34.

Carvalho, A. M. A., Müller, F., \& Sampaio, S. M. R. (2009). Sociologia da infância, psicologia do desenvolvimento e educação infantil: diálogos necessários. In F. Muller \& A. M. C. Carvalho (Org.), Teoria e prática na pesquisa com crianças - Diálogos com William Corsaro (pp. 189-204). São Paulo: Cortez.

Correia, M.F.B. (2009). Indeterminação, multidimensionalidade e relevância do processo de construção de significados. Psicologia em estudo, 14(1), 251-258.

Costa, C.A. (2008). Processo de “abreviação”, em relações de bebês com seus pares de idade. (Monografia de Bacharelado em Psicologia). Faculdade de Filosofia, Ciências e Letras de Ribeirão Preto, Universidade de São Paulo.

Êlmor, L.N.R. (2009). Recursos comunicativos utilizados por bebês em interação com diferentes interlocutores, durante processo de adaptação à creche: um estudo de caso. (Unpublished master's thesis). Faculdade de Filosofia, Ciências e Letras de Ribeirão Preto, Universidade de São Paulo.

Fogel, A. (1992). Movement and communication in human infancy: the social dynamics of development. Human Movement Science, 11, 387-423.

Franchi e Vasconcelos, C.R,. Amorim, K.S., Anjos, A.M., \& Rossetti-Ferreira, M.C. (2003). A incompletude como virtude: interação de bebês na creche. Psicologia Reflexão e Crítica, 16(2), 293-301.

Gerbelli, A.E. (2006). Desenvolvimento do contato ocular em bebês de zero a quatro meses. (Unpublished master's thesis). Faculdade de Filosofia, Letras e Ciências Humanas, Universidade de São Paulo.

Góes, M.C.R. (2000). A abordagem microgenética na matriz histórico-cultural: uma perspectiva para o estudo da constituição da subjetividade. Caderno Cedes, 20 (50), 9-25.

Goldin-Meadow, S. (2007). Pointing Sets the Stage for Learning Language and Creating Language. Child Development, 78(3), $741-745$.

Guimarães, D. (2008). Entre gestos e palavras: pistas para a educação das crianças de 0 a 3 anos. Retrieved from http:// www.maxwell.lambda.ele.puc-rio.br/.

Lyra, M.C.D.P. (2000). Desenvolvimento de um sistema de relações historicamente construído: contribuições da comunicação no início da vida. Psicologia Reflexão e Critica, 13(2), 257-268.
Lyra, M.C.D.P., \& Rossetti-Ferreira, M.C. (1995). Transformation and construction in social interaction: A new perspective on analysis of the mother infant dyad. In J. Valsiner (Org.), Child development within culturally structured environments, Vol. 3, Comparative cultural-constructivist perspective (pp. 51-77). Norwood, NJ: Ablex.

Lyra, M.C.D.P. (2007). O Modelo EEA: definições, unidade de análise e possíveis aplicações. Psicologia: Reflexão e Crítica, 20(1), 87-95.

Mendes, D. M. L. F., \& Seidl Moura, M. L. (2009). Expressões faciais de emoção em bebês: importância e evidências. Estudos de Psicologia, 9(2), 307-327.

Pozzebon, M., \& Freitas, H.M.R. (1998). Pela aplicabilidade - com um maior rigor científico - dos estudos de caso em sistemas de informação. Revista Administração Contemporânea, 2(2), 143-170.

Ribeiro, F. L., \& Bussab, V. S. R. (1998). Biologicamente cultural. In L. Souza, M. F. Q.

Freitas, \& M. M. P. Rodrigues (Orgs), Psicologia: reflexões (im) pertinentes (pp. 177- 203). São Paulo: Casa do psicólogo.

Rossetti-Ferreira, M.C., Amorim, K.S., \& Silva, A.P.S. (2000). Uma perspectiva teórico-metodológica para análise do desenvolvimento humano e do processo de investigação. Psicologia: Reflexão e Crítica, 13(2), 281-293.

Rossetti-Ferreira, M.C., Amorim, K.S., \& Silva, A.P.S. (2004). Rede de significações: alguns conceitos básicos. In M.C. RossettiFerreira, K.S. Amorim, A.P.S. Silva, \& A.M.A. Carvalho (Orgs.), Rede de significações e o estudo do desenvolvimento humano (pp. 23-34). Porto Alegre: Artmed.

Scorsolini-Comin, F., \& Amorim, K.S. (2010). Em meu gesto existe o teu gesto: corporeidade na inclusão de crianças deficientes. Psicologia: Reflexão e Crítica, 23(2), 261-269.

Seidl-Moura, M.L., \& Ribas, A.F.P. (2000). Desenvolvimento e contexto sociocultural: a gênese da atividade mediada nas interações iniciais mãe-bebê. Psicologia: Reflexão e Crítica, 13(2), 245-256.

Sinha, C., \& Rodríguez, C. (2008). Language and the signifying object: from convention to imagination. In J. Zlatev, T. Racine, C. Sinha \& E. Itkonen (Eds.) The Shared Mind: Perspectives on intersubjectivity (pp. 358-378), Amsterdam: John Benjamins.

Tomasello, M. (2003). Origens culturais da aquisição do conhecimento humano. São Paulo: Martins Fontes.

Tomasello, M., Carpenter, M., \& Liszkowski, U. (2007). A New Look at Infant Pointing. Child Development, 78(3), 705 - 722.

Vallotton, C. (2011). Babies open our minds to their minds: how listening to infant signs complements and extends our knowledge of infants and their development. Infant Mental Health Journal, 32(1), 115-133.

Vygotsky, L.S. (1991). A formação social da mente. São Paulo: Martins Fontes.

Wallon, H. (1979). Do ato ao pensamento. Lisboa: Moraes Editora.

Yin, R. K. (2005). Estudo de caso: planejamento e métodos. $3^{\mathrm{a}}$ edição. Porto Alegre: Bookman.

Recebido em 07.03.2013

Primeira decisão editorial em 04.09.2013

Versão final em 29.10.2013

Aceito em 29.10.2013 